\title{
Features of the Metabolic Syndrome in the Berlin Fat Mouse as a Model for Human Obesity
}

\author{
Claudia Hantschel ${ }^{\mathrm{a}} \quad$ Asja Wagener ${ }^{\mathrm{a}} \quad$ Christina Neuschl $^{\mathrm{a}} \quad$ Daniel Teupser $^{\mathrm{b}}$ \\ Gudrun A. Brockmann ${ }^{a}$ \\ a Department for Crop and Animal Sciences, Humboldt-Universität zu Berlin, \\ ${ }^{\mathrm{b}}$ Institute of Laboratory Medicine, Clinical Chemistry and Molecular Diagnostics, University Hospital Leipzig, Germany
}

\author{
Keywords \\ Obesity · Adipokines · Lipoproteins · Glucose clearance · \\ Insulin tolerance $\cdot$ Incretins
}

\section{Summary}

Background: The Berlin Fat Mouse BFMI860 is a polygenic obesity mouse model which harbors a natural major gene defect resulting in early onset of obesity. To elucidate adult bodily responses in BFMI860 mice that develop juvenile obesity, we studied features of the metabolic syndrome at 20 weeks. Methods: We examined fat deposition patterns, adipokines, lipid profiles in serum, glucose homeostasis, and insulin sensitivity in mice that were fed either a standard maintenance (SMD) or a high-fat diet (HFD). Results: Like many obese humans, BFMI860 mice showed hyperleptinemia accompanied by hypoadiponectinemia already at SMD that was further unbalanced as a result of HFD. Furthermore, BFMI860 mice had high triglyceride concentrations. However, triglyceride clearance after an oral oil gavage was impaired on SMD but improved on HFD. The oral and intraperitoneal glucose as well as the insulin tolerance tests provided evidence for reduced insulin sensitivity under SMD and insulin resistance on HFD. BFMI860 mice can maintain normal glucose clearance over a wide range of feeding conditions according to an adaptation via increasing the insulin concentrations. Conclusions: BFMI860 mice show obesity, dyslipidemia, and insulin resistance as three major components of the metabolic syndrome. As these mice develop the described phenotype as a result of a major gene defect, they are a unique model for the investigation of genetic and pathophysiological mechanisms underlying the observed features of the metabolic syndrome and to search for potential strategies to revert the adverse effects under controlled conditions.

\section{Introduction}

Obesity, in particular central obesity, and insulin resistance are two major components of the metabolic syndrome [1-4] that describe a complex of independent metabolic risk factors including increased waist circumference, dyslipidemia (elevated triglycerides, low-density lipoprotein cholesterol and reduced high-density lipoprotein cholesterol), fasting hyperglycemia, and hypertension [5-7]. These factors mostly occur together and increase the lifetime risk of cardiovascular disease and type 2 diabetes [1]. Because obesity is closely associated with the occurrence of insulin resistance, common pathophysiological causes of the features of the metabolic syndrome are suspected but remain to be elucidated $[8,9]$. In addition, the role of the adipose tissues as active endocrine organs has to be considered for the detection of endocrine abnormalities (in adipokines, cytokines) as independent and emerging risk factors for the metabolic syndrome and later diseases [10].

Leptin and adiponectin are the most abundant adipokines primarily secreted by the adipocytes [11]. Leptin is an essential hormonal regulator of metabolism and neuroendocrine function that signals energy insufficiency or excess to the brain [12]. In steady-state conditions of energy supply, leptin concentrations correlate well with the amount of adipose tissue [13]. Adiponectin has insulin-sensitizing effects and exerts

\section{KARGER}

Fax +497614520714

Information@Karger.de

www.karger.com (c) 2011 S. Karger GmbH, Freiburg

$1662-4025 / 11 / 0044-0270 \$ 38.00 / 0$

Accessible online at:

www.karger.com/ofa
Gudrun A. Brockmann

Breeding Biology and Molecular Genetics, Department for Crop and Animal Sciences Humboldt-Universität zu Berlin

Invalidenstraße 42, 10115 Berlin, Germany

Tel. +49 30 2093-6449/6089, Fax -6397

gudrun.brockmann@agrar.hu-berlin.de 
its action via AMPK in suppressing gluconeogenesis and enhancing lipid oxidation in liver and muscle [14]. In obesity, the balance of adipokines is altered [15]. Hyperleptinemia points to insensitivity of the body to endogenous leptin production, similar to the insulin resistance of type 2 diabetes [16, 17]. In contrast to leptin, adiponectin levels are decreased in obesity $[18,19]$, also contributing to the impaired insulin sensitivity.

Because multiple clinical facets of the metabolic syndrome are known, there is an urgent demand for animal models that reproduce as close as possible the underlying spectrum of conditions coexisting in patients. Inbred strains of mice complement the search for genetic components of human diseases as well as the understanding of the biological and disease process investigations which can be performed under controlled environmental and genetic conditions [20,21]. The Berlin Fat Mouse Inbred line 860 (BFMI860) harbors several gene variants contributing to obesity [22]. A major gene defect on mouse chromosome 3 is responsible for the highest fat mass gain and occurs during the juvenile phase of development that corresponds to humans aged between 12 and 20 years [23, 24]. The excessive adiposity in BFMI860 mice is associated with higher energy digestion, higher respiratory quotients, and a fatty liver syndrome [25].

To elucidate bodily responses in adult BFMI860 mice that develop juvenile obesity, we studied features of the metabolic syndrome. We characterized BFMI860 mice in terms of pathophysiological changes leading to adipokine abnormalities, dyslipidemia, and impaired glucose and insulin tolerance in 20-week-old mice. Because high-fat diet is a nutritional condition that accounts for the largest incidence of the metabolic syndrome, we performed a feeding experiment in which BFMI860 mice were fed either a standard or a high-fat diet.

\section{Material and Methods}

\section{Mice, Diets and Housing Conditions}

The study was carried out on the Berlin Fat Mouse Inbred line 860 (BFMI860; Department for Crop and Animal Sciences, Humboldt-Universität zu Berlin, Berlin, Germany). BFMI860 is an inbred derivative of the Berlin Fat Mouse (BFM), an outbred, high fatness-selected population [22]. To control the environmental conditions, C57BL/6NCrl (B6; Charles River Laboratories, Sulzfeld, Germany) was used as a reference line. We wish to mention that the C57BL/6NCrl (B6) line differs genetically from C57BL/6J, which is most often used as a control line. The subline divergence occurred during the maintenance of mouse stocks in different subpopulations over many generations and is a major reason for phenotypic differences seen between different B6 sublines [26, 27].

Three-week-old BFMI860 $(\mathrm{n}=44)$ and B6 $(\mathrm{n}=54)$ males were separated into two feeding groups and were placed on either a standard maintenance diet (SMD) or a high-fat diet (HFD) for 17 weeks. The SMD (V1534-000 ssniff R/M-H; ssniff Spezialdiäten GmbH, Soest, Germany) had a gross energy content of $12.8 \mathrm{MJ} / \mathrm{kg}$ ( $9 \%$ of calories from fat, $33 \%$ from protein, and 58\% from carbohydrates). The HFD (S8074-E010 ssniff EF R/M; ssniff Spezialdiäten $\mathrm{GmbH}$ ) had a gross energy content of $19.1 \mathrm{MJ} / \mathrm{kg}$ (45\% of calories from fat, $24 \%$ from protein, and $31 \%$ from carbohydrates). The main source of fat in the SMD was soy oil, whereas the fat in the HFD was coconut oil and suet. Data on the food composition were provided by the producer. Animals had ad libitum access to food and water throughout the experiment. They were housed at 12-hour light/dark cycles (light on at 6:00 a.m.). All animal treatments were in accordance with the German Animal Welfare Legislation (approval no. G0301/08).

\section{Mouse Phenotyping and Blood Serum Collection}

Beginning at weaning, mice were weighed weekly to examine body weight gain. Body fat mass and body lean mass were measured biweekly in non-anesthetized mice by quantitative magnetic resonance (QMR) analysis using the EchoMRI whole body composition analyzer (Echo Medical Systems, Houston, TX, USA) [28, 29]. QMR measurements were performed in duplicate, and the mean was used for further analyses.

At 20 weeks, mice were sacrificed between 9 and 12 a.m. after a fasting period of $2 \mathrm{~h}$. To obtain the largest possible blood volume, blood was obtained at necropsy after cervical dislocation. Blood plasma aliquots were directly used after dissection for the determination of cholesterol and triglyceride distribution in lipoprotein fractions. For the measurement of leptin, adiponectin and insulin, serum was stored at $-20{ }^{\circ} \mathrm{C}$ until use. White adipose tissues (subcutaneous, epididymal) were dissected and immediately weighed.

\section{Serum Hormone and Lipoprotein Analyses}

Serum leptin and adiponectin were determined by enzyme-linked immunosorbent assay (ELISA) kits (mediagnost, Reutlingen, Germany, and R and D Systems, Wiesbaden, Germany, respectively). For leptin, samples were diluted $1 / 10 \mathrm{v} / \mathrm{v}$ with dilution buffer. For adiponectin, samples were diluted 1/5,000 v/v or 1/8,000 v/v with Reagent Diluent. According to the manufacturer, intra-assay coefficients of variation were $4.4 \%$ and $5.8 \%$, and inter-assay coefficients of variation were $4.7 \%$ and $6.0 \%$ with sensitivities of 0.01 and $0.003 \mathrm{ng} / \mathrm{ml}$ for mouse leptin and adiponectin, respectively. Serum insulin was measured with an Insulin Mouse Ultrasensitive ELISA Kit from DRG Instruments GmbH (Marburg, Germany). Intraassay coefficient of variation was $8.7 \%$ and inter-assay coefficient of variation was $7.8 \%$, with sensitivity of $0.188 \mathrm{ng} / \mathrm{ml}$ for mouse insulin according to the manufacturer's protocol.

Serum triglycerides were measured by enzymatic colorimetric method using commercial test kits (Biocon, Burbach, Germany) that were adapted for microtiter plates.

Lipoproteins were separated from blood serum by sequential ultracentrifugation, and cholesterol and triglyceride distribution in lipoprotein fractions were determined using a colorimetric method (Roche) as described previously [30].

\section{Glucose, Insulin, and Fat Tolerance Tests}

To assess glucose tolerance, an intraperitoneal glucose tolerance test (ipGTT) was performed. To evaluate fasted insulin secretion and insulin resistance, which are key phenotypes of type 2 diabetes, an intraperitoneal insulin tolerance test (ipITT) was conducted. To consider the incretin effect, oral glucose tolerance tests (oGTT) were performed. Plasma triglyceride clearance was determined during oral fat tolerance tests (oFTT) by oral gavage of olive oil.

For all tolerance tests, subsets of mice at 20 weeks, fed either the SMD or HFD as described above, were used. In each feeding group, 5-9 BFMI860 and B6 males were used. Mice were fasted for 12-14 h (ipGTT, oGTT, oFTT) or $4 \mathrm{~h}$ (ipITT). After a baseline blood sample was taken (0 min), glucose (B. Braun, Melsungen, Germany) was given intraperitoneally [31] or orally at a dose of $2 \mathrm{mg} / \mathrm{g}$ body weight. For the ipITT, insulin was given intraperitoneally at a dose of $1 \mathrm{U} / \mathrm{kg}$ body weight. For the measurement of glucose concentrations, blood was obtained from the tail tip at 15, 30, 60, and $120 \mathrm{~min}$ for ipGTT and oGTT, and at 15, 30, and $60 \mathrm{~min}$ for ipITT. For the oFTT, $10 \mu \mathrm{l}$ olive oil/g body weight was administered. Aliquots of tail vein blood were collected for the determination of triglyceride concentrations immediately before and at 2, 3, 4, 6 and $12 \mathrm{~h}$ after the oral bolus load. 
Table 1. Body composition and blood parameters of 20-week-old BFMI860 and B6 mice fed a standard maintenance or high-fat diet for 17 weeks

\begin{tabular}{|c|c|c|c|c|}
\hline \multirow[t]{2}{*}{ Trait $^{\#}$} & \multicolumn{2}{|l|}{ BFMI860 } & \multicolumn{2}{|l|}{ B6 } \\
\hline & SMD & HFD & SMD & HFD \\
\hline Total body weight, $\mathrm{g}$ & $44.0 \pm 0.7$ & $55.7 \pm 2.7$ & $27.1 \pm 1.6$ & $28.8 \pm 2.2$ \\
\hline Total fat mass, $\%$ & $28.2 \pm 1.7$ & $33.5 \pm 1.4^{++}$ & $6.2 \pm 3.3^{* * *}$ & $11.6 \pm 4.0^{* * *,++}$ \\
\hline Subcutaneous adipose tissue, $\mathrm{g}$ & $2.1 \pm 0.8$ & $3.6 \pm 0.7^{+}$ & $0.3 \pm 0.1^{* *}$ & $0.6 \pm 0.3^{* *,+}$ \\
\hline Epididymal adipose tissue, $\mathrm{g}$ & $2.6 \pm 0.6$ & $2.7 \pm 0.6$ & $0.3 \pm 0.1^{* *}$ & $0.5 \pm 0.3^{* *,+}$ \\
\hline Total lean mass, $\%$ & $64.3 \pm 1.4$ & $60.1 \pm 1.3^{++}$ & $84.4 \pm 2.8^{* * * *}$ & $79.4 \pm 4.3^{* * *,+}$ \\
\hline Glucose, $\mathrm{mmol} / \mathrm{l}$ & $8.9 \pm 2.7$ & $13.0 \pm 9.5$ & $7.2 \pm 0.9$ & $7.4 \pm 1.0$ \\
\hline Insulin, ng/ml & $13.5 \pm 12.5$ & $61.3 \pm 58.4$ & $0.9 \pm 0.8$ & $1.6 \pm 0.9^{*}$ \\
\hline Cholesterol, $\mathrm{mmol} / \mathrm{l}$ & $2.3 \pm 0.4$ & $4.5 \pm 0.6^{+++}$ & $2.5 \pm 0.4$ & $4.3 \pm 1.2^{++}$ \\
\hline HDL-cholesterol, mmol/l & $1.2 \pm 0.5$ & $2.1 \pm 0.3^{++}$ & $1.3 \pm 0.3$ & $2.2 \pm 0.4^{++}$ \\
\hline LDL-cholesterol, mmol/l & $0.7 \pm 0.2$ & $1.8 \pm 0.5^{+++}$ & $0.9 \pm 0.2$ & $1.9 \pm 0.7^{++}$ \\
\hline VLDL-cholesterol, mmol/1 & $0.4 \pm 0.1$ & $0.6 \pm 0.2$ & $0.3 \pm 0.1$ & $0.3 \pm 0.1^{* *}$ \\
\hline Triglycerides, mmol/1 & $3.2 \pm 0.9$ & $3.6 \pm 0.6$ & $1.2 \pm 0.4^{* *}$ & $1.4 \pm 0.1^{* * *}$ \\
\hline VLDL-triglycerides, mmol/l & $1.5 \pm 0.4$ & $.7 \pm 0.4$ & $0.4 \pm 0.2^{* * *}$ & $0.4 \pm 0.1^{* * * *}$ \\
\hline Leptin, ng/ml & $25.2 \pm 4.8$ & $34.8 \pm 1.0^{+}$ & $2.0 \pm 1.3^{* * * *}$ & $3.6 \pm 3.5^{* *}$ \\
\hline Leptin-fat-ratio, $\mathrm{ng} / \mathrm{ml} / \mathrm{g}$ & $1.2 \pm 0.5$ & $2.2 \pm 0.4$ & $1.0 \pm 0.6^{* *}$ & $1.9 \pm 0.2^{* *}$ \\
\hline Adiponectin, $\mu \mathrm{g} / \mathrm{ml}$ & $3.1 \pm 1.0$ & $1.7 \pm 0.3^{+}$ & $5.5 \pm 1.6^{* *}$ & $4.5 \pm 0.5^{* * *}$ \\
\hline HOMA-IR & $5.1 \pm 3.8$ & $30.5 \pm 16.2^{++}$ & $1.0 \pm 0.9^{*}$ & $2.3 \pm 1.8^{* *}$ \\
\hline
\end{tabular}

HFD = High-fat diet; HOMA-IR = homeostasis model assessment of insulin resistance; SMD = standard maintenance diet; total fat mass $(\%)=$ fat mass percentage relative to body weight; total lean mass $(\%)=$ lean mass percentage relative to body weight.

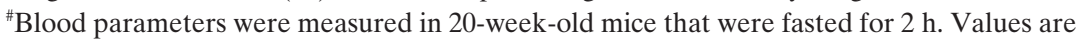
mean \pm SD. Data were analyzed by Welch's t-test to evaluate the differences between groups. ${ }^{*} \mathrm{p}<0.05 ;{ }^{* * *} \mathrm{p}<0.01 ;{ }^{* * *} \mathrm{p}<0.001$ for line effects; ${ }^{+} \mathrm{p}<0.05 ;{ }^{++} \mathrm{p}<0.01 ;{ }^{+++} \mathrm{p}<0.001$ for diet effects.
Blood glucose concentration was measured with the glucose analyzer Ascensia Elite (Bayer HealthCare AG, Leverkusen, Germany) To minimize distress, mice were kept in their accustomed cages and had free access to water. To assess glucose and fat tolerance, the area under the curve (AUC) was calculated between 0 and $120 \mathrm{~min}$ after glucose injection $(\mathrm{mmol} / \mathrm{l} \times 120 \mathrm{~min})$, between 0 and $60 \mathrm{~min}$ after insulin injection $(\mathrm{mmol} / 1 \times 60 \mathrm{~min})$, and between 0 and $12 \mathrm{~h}$ after oil gavage $(\mathrm{mmol} / \mathrm{l} \times 12 \mathrm{~h})$.

To roughly determine insulin sensitivity and resistance, the homeostasis model assessment of insulin resistance (HOMA-IR) was calculated from the product of fasting glucose $(\mathrm{mg} / \mathrm{dl})$ and insulin $(\mathrm{ng} / \mathrm{ml})$ divided by $22.5[32,33]$.

\section{Statistics}

We performed an ANOVA with the general linear model to assess the effects of line (BFMI860/B6), diet (SMD/HFD) and all possible two-way interactions of the measured traits. Welch's t-test was used to evaluate the differences between the groups. Data is given as means \pm standard deviation (SD). Differences were considered statistically significant at $\mathrm{p}<0.05$. All analyses were performed using the statistical package R 2.10.1 [34].

\section{Results}

\section{Response of the BFMI860 Mouse to Diets on Body \\ Composition}

BFMI860 mice harbor a natural mutation leading to early onset of obesity. BFMI860 mice are 1.6 times heavier than B6 mice at weaning ( 3 weeks of age) and show highest fat mass gain between 6 and 10 weeks [22]. Most fat is deposited in gonadal and subcutaneous adipose tissues. At 20 weeks, BFMI860 mice had on average 5 and 3 times as much body fat relative to their body weights as B6 mice on SMD and HFD, respectively ( $p<0.001$; table 1$)$. On HFD, additional fat was accumulated mainly in subcutaneous adipose tissue $(\mathrm{p}<0.05$; table 1).

\section{Hyperleptinemia and Hyoadiponectinemia of the BFMI860 Mouse}

Due to the high body fat mass, serum leptin concentrations were highly increased in BFMI860 mice as compared to B6 mice. On SMD, BFMI860 mice had 5 times more fat mass, but 13 times higher serum leptin concentrations than B6 mice ( $\mathrm{p}<0.001$; table 1); on HFD, BFMI860 mice had 3 times more fat mass and 10 times higher serum leptin concentrations. The leptin-to-fat ratios give a hint on the production of leptin in the adipocytes. These are marginally but significantly higher in BFMI860 mice, independently of the diet (1.2-fold for both diets, $\mathrm{p}<0.01)$. The results suggest that the production and secretion of leptin on the cellular level of adipose tissues is little higher in BFMI860 than in B6 mice.

Hypoadiponectinemia was observed in BFMI860 mice. Consistent with the high body fat mass on SMD, BFMI860 mice had $44 \%$ lower serum adiponectin concentrations than B6 mice ( $\mathrm{p}<0.01$; table 1). BFMI860 mice responded to HFD 
(a) SMD, oral fat tolerance test
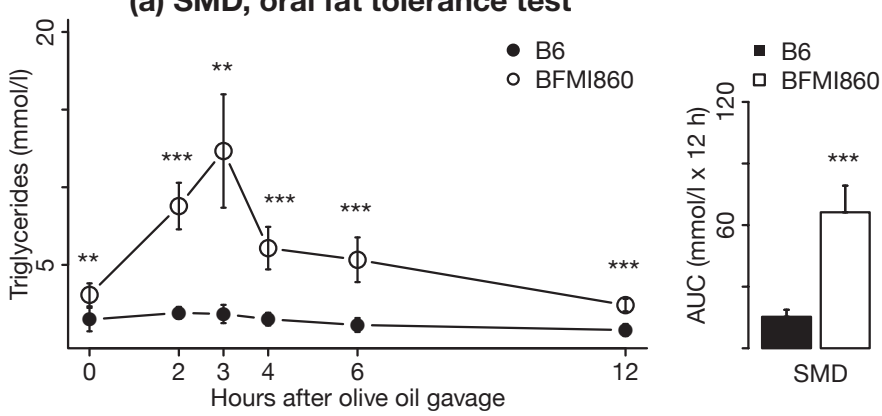

Fig. 1. Oral fat tolerance test in BFMI860 mice fed a standard maintenance or high-fat diet $(\mathrm{n}=5)$. $(\mathbf{a}, \mathbf{b})$ Triglyceride concentrations during fat tolerance test (oFTT) and triglyceride AUC in overnight-fasted (13 h) (b) HFD, oral fat tolerance test
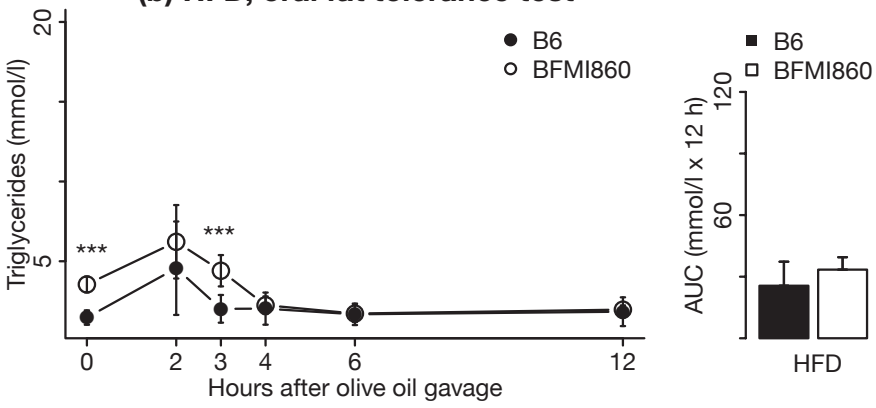

mice to evaluate the triglyceride clearance in response to an oral fat load (olive oil, $10 \mu \mathrm{l} / \mathrm{g}$ ). B6 was used as lean control mouse line. Results are means \pm SD. Significant differences were observed: ${ }^{* * *} \mathrm{p}<0.001 ;{ }^{* * *} \mathrm{p}<0.01$. with further strong reduction of the serum adiponectin concentration down to $1.7 \mu \mathrm{g} / \mathrm{ml}$, which were about half of the adiponectin concentrations found on SMD and which were markedly lower than in B6 mice $(\mathrm{p}<0.001)$.

\section{Elevated Plasma Triglyceride and VLDL-Cholesterol \\ Concentrations in the BFMI860 Mouse}

Concentrations of total cholesterol and subfractions of cholesterol did not differ between lines on either diet. Both lines responded to HFD with hypercholesterolemia; HDL- and LDLcholesterol fractions were increased equally in both lines. Marginally higher cholesterol concentrations in VLDL were found in BFMI860 mice on HFD. To exclude a higher risk for atherosclerosis in BFMI860 mice, we examined BFMI860 males and females at the age of 30 weeks for aortic lesion formation. The results did not indicate the formation of atherosclerotic plaques or lesions in the aorta (data not shown).

BFMI860 mice showed hypertriglyceridemia and increased triglyceride concentrations in VLDL on both diets $(p<0.01$, table 1). There was no difference between mice on SMD and HFD. The oFTT provided evidence for impaired fat uptake into tissues in BFMI860 mice on SMD, but not on HFD (fig. 1). On SMD, the serum triglyceride concentrations increased 5-fold over $3 \mathrm{~h}$ after olive oil gavage before they dropped slowly. On HFD, the peak triglyceride concentration was measured $2 \mathrm{~h}$ after olive oil gavage and reached the basal concentration already 1-2 h later (fig. 1b).

\section{Impaired Glucose Tolerance and Insulin Resistance of the BFMI860 Mouse}

After a fasting period of $2 \mathrm{~h}$, BFMI860 mice tended to have higher blood glucose concentrations on SMD and in particular on HFD, but they did not differ significantly from B6 since BFMI860 mice had higher variances (table 1). BFMI860 mice had 3 and 9.5 times higher standard deviation than B6 mice on SMD and HFD, respectively. BFMI860 mice had also conspicuously higher insulin values than B6 mice, which were sig- nificant on HFD ( $p<0.05$; table 1$)$. Because of the similar glucose concentrations and the elevated serum insulin concentrations in BFMI860 mice compared to B6, we examined glucose tolerance and insulin sensitivity.

The oGTT, the ipGTT, and the ipITT provided evidence for insulin resistance in BFMI860 mice. The first hint gave the HOMA-IR index, which is based on the fasting serum glucose and insulin concentrations. High values are an indication for insulin resistance. The HOMA-IR indices were significantly increased in BFMI860 mice on both diets, particularly on HFD $(\mathrm{p}<0.01$, table 1$)$.

On SMD, the glucose tolerance was moderately affected, while on HFD the glucose clearance was impaired. BFMI860 mice on SMD showed normal glucose clearance after oral glucose administration (fig. 2a), but, delayed glucose clearance after intraperitoneal glucose administration (fig. 2c). In both tests, BFMI860 mice had higher serum insulin concentrations. Due to the incretin effect [35, 36], BFMI860 mice in the oGTT showed a marginal increase of serum insulin concentrations during the first 30 min after oral glucose administration (fig. 2e); no increase of insulin was measured in mice after intraperitoneal injection of glucose (fig. 2g). Furthermore, the glucose concentration in BFMI860 mice was not affected by intraperitoneal administration of insulin (fig. 3a).

During HFD feeding over 17 weeks, BFMI860 mice developed insulin resistance. The glucose clearance was delayed not only during the ipGTT (fig. 2d) but also during the oGTT (fig 2b). Compared with glucose clearance in B6 mice, BFMI860 mice needed a similar time to clear glucose, but the glucose peak 15-30 min after glucose administration in BFMI860 mice was below that of B6 mice. Albeit the glucose clearance in the oGTTs of BFMI860 mice did not differ significantly between mice on SMD (fig. 2a) and HFD (fig. 2b), the clearance was possible only under highly increased insulin concentrations, which BFMI860 mice had already before glucose administration (fig. $2 \mathrm{f}, \mathrm{h}$ ), after fasting overnight. An increase of insulin after oral glucose ad- 
(a) SMD, oral glucose tolerance test

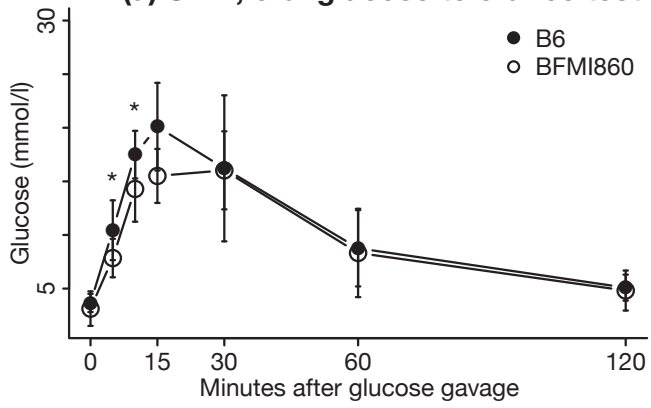

(c) SMD, ip glucose tolerance test
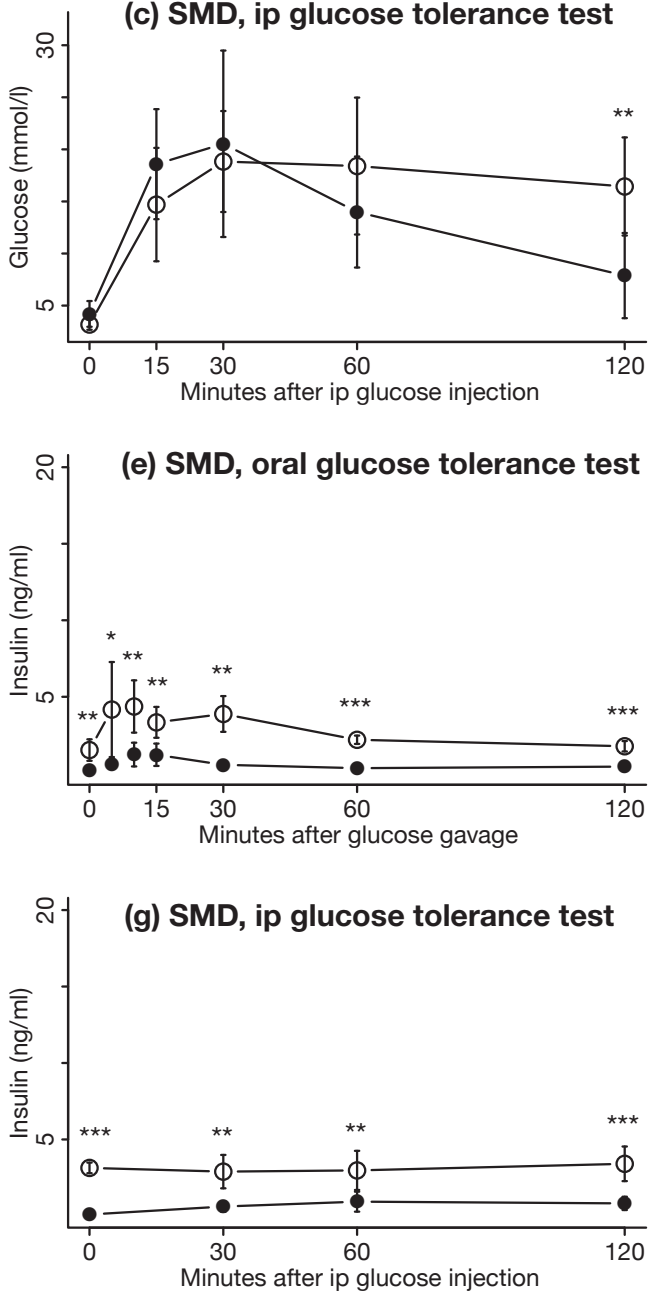

Fig. 2. Glucose tolerance test in BFMI860 mice fed a standard maintenance or high-fat diet $(\mathrm{n}=5)$. $(\mathbf{a}, \mathbf{b})$ oGTT and $(\mathbf{c}, \mathbf{d})$ ipGTT were performed after a 14-hour fasting period. Blood samples for insulin determination were collected from the tail during oGTT $(\mathbf{e}, \mathbf{f})$ and ipGTT

ministration could not be detected (fig. 2f). Further evidence for insulin resistance in BFMI860 mice on HFD was provided by the ipITT. The injection of additional insulin had no positive effect on glucose clearance. In contrast, $15 \mathrm{~min}$ after insulin injection, the serum glucose concentration was even higher than before (fig. 3b). (b) HFD, oral glucose tolerance test
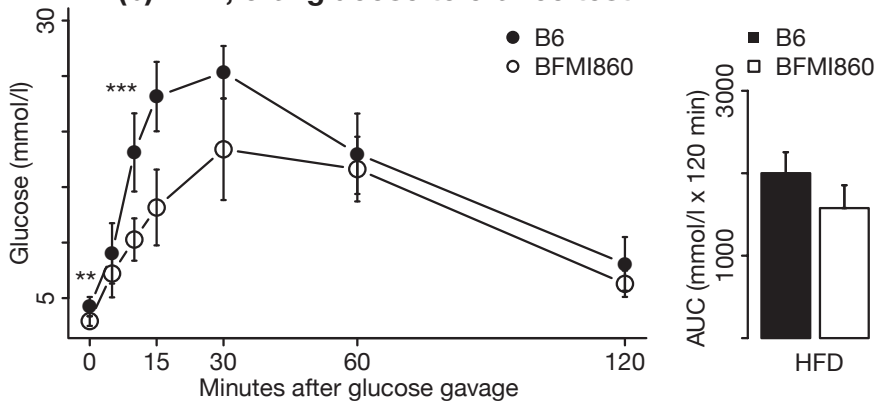

(d) HFD, ip glucose tolerance test
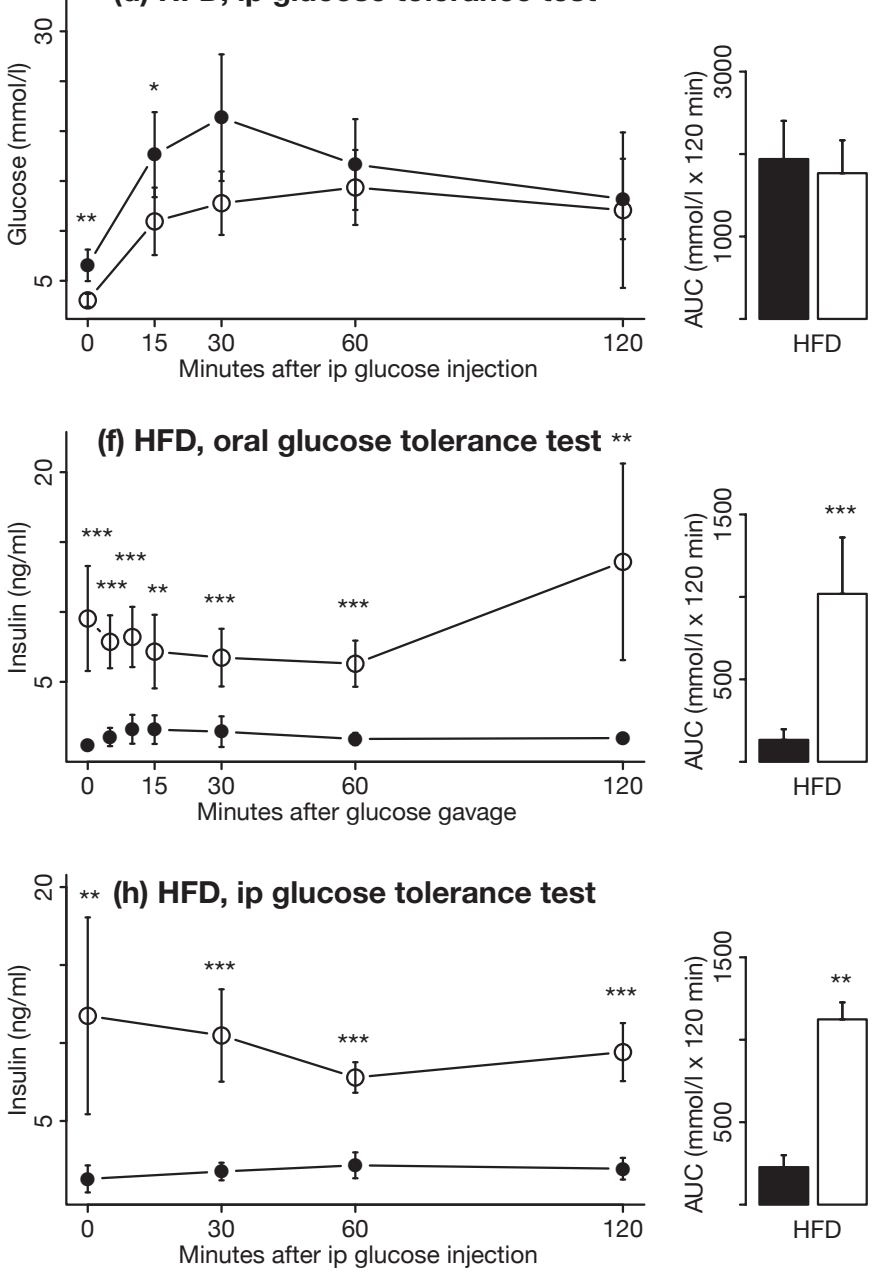

$(\mathbf{g}, \mathbf{h})$. Glucose AUC and insulin AUC were calculated to evaluate the response to oGTT and ipGTT. B6 was used as lean control mouse line. Results are means \pm SD. Significant differences were observed: ${ }^{* * * *} \mathrm{p}<0.001$; ${ }^{* * *} \mathrm{p}<0.01 ;{ }^{*} \mathrm{p}<0.05$

\section{Discussion}

Several risk factors describe the metabolic syndrome. The main components are central obesity, insulin resistance, dyslipidemia, and hypertension [6]. The presented data demonstrate that BFMI860 mice have i) central and peripheral obe- 
(a) SMD, ip insulin tolerance test
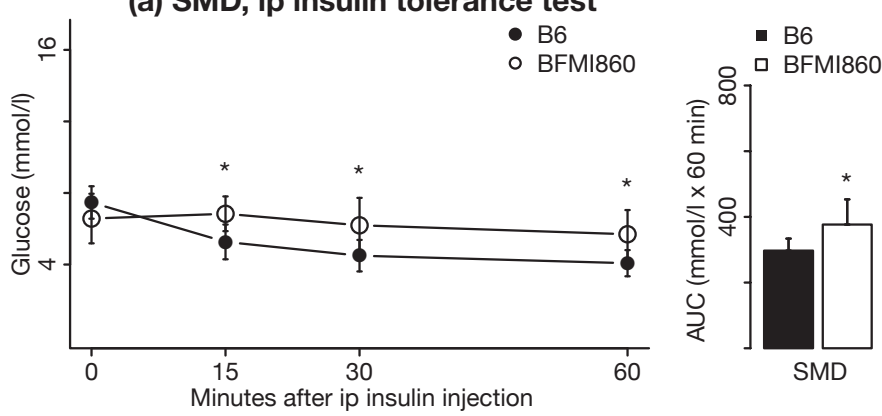

Fig. 3. Insulin tolerance test in BFMI860 mice fed a standard maintenance or high-fat diet $(\mathrm{n}=5)$. ipITT $(\mathbf{a}, \mathbf{b})$ was performed after a 4-hour fasting period. Glucose AUC was calculated to evaluate the response to (b) HFD, ip insulin tolerance test

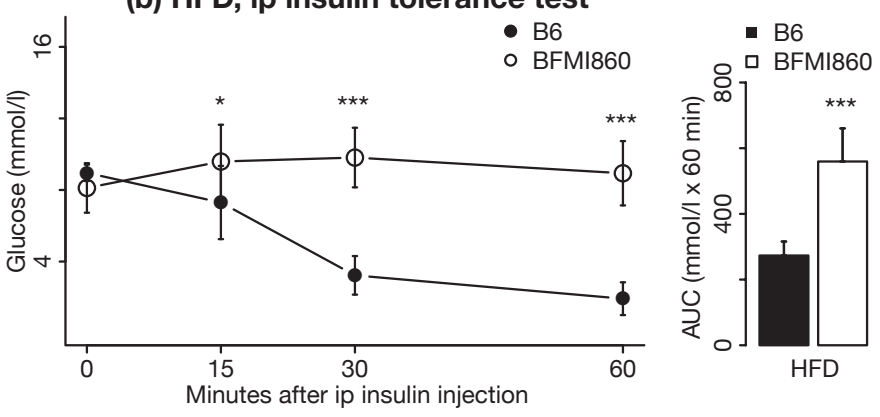

ipITT. B6 was used as lean control mouse line. Results are means \pm SD. Significant differences were observed: ${ }^{* * *} \mathrm{p}<0.001 ;{ }^{*} \mathrm{p}<0.05$.

crease of serum glucose after intraperitoneal insulin injection in HFD-fed BFMI860 mice is likely the result of continued glucose synthesis in the liver and secretion into the blood while insulin-mediated glucose uptake into target tissues, particularly into the muscle, is disturbed. The elevated glucose concentration in the serum after insulin injection also suggests a higher insulin resistance in the muscle compared to the liver in BFMI860 mice.

We furthermore expected a difference in glucose clearance between the oGTTs and ipGTTs. As a consequence of the incretin effect, after oral glucose administration higher insulin secretion leading to higher serum insulin concentrations, and faster glucose clearance were expected than after intraperitoneal injection. However, we found only marginally elevated insulin concentrations during the oGTT in BFMI860 mice on SMD, but not on HFD. The consistently elevated serum concentration of insulin in junction with low insulin sensitivity likely impairs signal transduction to induce additional insulin secretion. However, we cannot exclude that we missed the insulin peak due to the time regime of blood sampling, albeit we measured insulin every $5 \mathrm{~min}$ after glucose injection during the first $15 \mathrm{~min}$.

The low insulin sensitivity might also be responsible for the low and delayed lipid clearance of BFMI860 mice on SMD. However, during the long feeding period of 17 weeks with HFD, BFMI860 mice likely went through a process of adaptation to HFD that led to an improved triglyceride uptake into target tissues after either high-fat feeding or oral fat administration. During this adaptational phase, HFD induces a transformation of adipose tissue that leads to a change of the functioning of the cells. The process is accompanied by increased leptin production and inhibition of adiponectin synthesis and secretion, which in turns may affect the insulin action [38-40].

The increased lipid uptake in BFMI860 mice on HFD could not only lead to higher fat accumulation in adipose tissues but also to increased ectopic fat storage in the liver, muscle, and other tissues that do not typically store fat. BFMI860 mice on HFD show steatosis, which indicate higher lipid accumulation. 
It has been suggested that insulin resistance is the first 'prediabetic' step of a two-step process characterized by reduced insulin sensitivity where compensatory hyperinsulinemia helps to maintain blood glucose concentrations [41]. In a second step, the pancreatic beta cells' secretory capacity may decline along with progressively elevated glucose concentrations leading to type 2 diabetes. Our mice are able to maintain normal blood glucose concentrations for a long time. They develop type 2 diabetes until 30 weeks only in rare cases (about 1\%; unpublished data). We consider a mouse diabetic if the blood glucose concentration is higher than $250 \mathrm{mg} / \mathrm{dl}$ after $2 \mathrm{~h}$ of fasting in subsequent measurements every other week, as recommended by Clee and Attie [26]. It is possible that features of the metabolic syndrome occur without increasing the risk of later onset of severe diseases [42]. For example, 'healthy' obese individuals are known, but the mechanisms leading to the switch between complications and prevention or circumvention of regulatory dysfunctions are still unknown.

In our fat BFMI860 mice, hypersecretion of insulin might be a compensatory mechanism to maintain euglycemia in the setting of insulin resistance. As several mouse models for monogenic or polygenic obesity like NZO [43], KK [44], and M16 [45] develop diabetes at early ages, the obese BFMI860 line constitutes a unique model to identify mechanisms and causes of both obesity and eventually the development of type 2 diabetes in high-aged individuals.

\section{Conclusion}

In conclusion, the data presented here suggest that BFMI860 mice present three of four major components of the metabolic syndrome. These include obesity, dyslipidemia, and insulin resistance. Hypersecretion of insulin in these mice as an adaptive mechanism is required to avoid hyperglycemia. However, under high-fat feeding, this phenotype becomes threatening by the development of insulin resistance. As a major gene defect on chromosome 3 is responsible for the juvenile obesity, the BFMI860 mice present a unique model for the investigation of genetic and cellular mechanisms underlying the observed features of the metabolic syndrome and to search for potential targets that counterbalance risk factors.

\section{Acknowledgments}

The project was funded by grants from the National Genome Research Network (NGFNplus, registration no. 01GS0829) and the German Research Foundation (DFG Graduate College 1208 'Hormonal Regulation of Energy Metabolism, Body Weight and Growth').

\section{Disclosure Statement}

The authors declared no conflicts of interest.

\section{References}

1 Grundy SM: Does a diagnosis of metabolic syndrome have value in clinical practice? Am J Clin Nutr 2006;83:1248-1251.

2 American Heart Association; National Heart, Lung, and Blood Institute; Grundy SM, Cleeman JI, Daniels SR, Donato KA, Eckel RH, Franklin BA, Gordon DJ, Krauss RM, Savage PJ, Smith SC, Spertus JA, Costa F: Diagnosis and management of the metabolic syndrome: an American Heart Association/National Heart, Lung, and Blood Institute scientific statement. Executive summary. Cardiol Rev 2005;13:322-327.

$\checkmark 3$ Grundy SM: Drug therapy of the metabolic syndrome: minimizing the emerging crisis in polypharmacy. Nat Rev Drug Discov 2006;5:295-309.

4 Kahn BB, Flier JS: Obesity and insulin resistance. J Clin Invest 2000;106:473-481.

$\checkmark 5$ Despres JP, Lemieux I: Abdominal obesity and metabolic syndrome. Nature 2006;444:881-887.

6 Alberti KGMM, Eckel RH, Grundy SM, Zimmet PZ, Cleeman JI, Donato KA, Fruchart JC, James WP, Loria CM, Smith SC Jr, International Diabetes Federation Task Force on Epidemiology and Prevention, National Heart, Lung, and Blood Institute, American Heart Association, World Heart Federation, International Atherosclerosis Society, International Association for the Study of Obesity: Harmonizing the metabolic syndrome: a joint interim statement of the International Diabetes Federation Task Force on Epidemiology and Prevention; National Heart, Lung, and Blood Insti- tute; American Heart Association; World Heart Federation; International Atherosclerosis Society; and International Association for the Study of Obesity. Circulation 2009;120:1640-1645.

7 Eckel RH, Alberti KGMM, Grundy SM, Zimmet PZ: The metabolic syndrome. Lancet 2010;375: 181-183.

8 DeFronzo RA, Ferrannini E: Insulin resistance. A multifaceted syndrome responsible for NIDDM, obesity, hypertension, dyslipidemia, and atherosclerotic cardiovascular disease. Diabetes Care 1991;14:173-194.

9 McFarlane Samy I, Banerji Maryann, Sowers James R: Insulin resistance and cardiovascular disease. J Clin Endocrinol Metab 2001;86:713-718.

10 Kershaw EE, Flier JS: Adipose tissue as an endocrine organ. J Clin Endocrinol Metab 2004;89: 2548-2556.

11 Tilg H, Moschen AR: Adipocytokines: mediators linking adipose tissue, inflammation and immunity. Nat Rev Immunol 2006;6:772-783.

12 Flier JS: Clinical review 94: What's in a name? In search of leptin's physiologic role. J Clin Endocrinol Metab 1998;83:1407-1413.

13 Friedman JM, Halaas JL: Leptin and the regulation of body weight in mammals. Nature 1998;395:763770 .

14 Kadowaki T, Yamauchi T: Adiponectin and adiponectin receptors. Endocr Rev 2005;26:439-451.

15 Attie AD, Scherer PE: Adipocyte metabolism and obesity. J Lipid Res 2009;50(suppl):S395-S399.
6 Frederich RC, Hamann A, Anderson S, Lollmann B, Lowell BB, Flier JS: Leptin levels reflect body lipid content in mice: Evidence for diet-induced resistance to leptin action. Nat Med 1995;1:1311-1314.

17 Caprio S, Tamborlane WV, Silver D, Robinson C, Leibel R, McCarthy S, Grozman A, Belous A Maggs D, Sherwin RS: Hyperleptinemia: an early sign of juvenile obesity. Relations to body fat depots and insulin concentrations. Am J Physiol Endocrinol Metab 1996;271:E626-E630.

18 Arita Y, Kihara S, Ouchi N, Takahashi M, Maeda K, Miyagawa J, Hotta K, Shimomura I, Nakamura T, Miyaoka K, Kuriyama H, Nishida M, Yamashita S, Okubo K, Matsubara K, Muraguchi M, Ohmoto Y, Funahashi T, Matsuzawa Y: Paradoxical decrease of an adipose-specific protein, adiponectin, in obesity. Biochem Biophys Res Commun 1999; 257:79-83.

19 Weyer C, Funahashi T, Tanaka S, Hotta K, Matsuzawa Y, Pratley RE, Tataranni PA: Hypoadiponectinemia in obesity and type 2 diabetes: Close association with insulin resistance and hyperinsulinemia. J Clin Endocrinol Metab 2001;86:1930 1935.

20 Taft RA, Davisson M, Wiles MV: Know thy mouse. Trends Genet 2006;22:649-653.

21 Nguyen D, Xu T: The expanding role of mouse genetics for understanding human biology and disease. Dis Model Mech 2008;1:56-66. 
22 Wagener A, Schmitt AO, Aksu S, Schlote W, Neuschl C, Brockmann GA: Genetic, sex, and diet effects on body weight and obesity in the Berlin Fat Mouse Inbred lines. Physiol Genom 2006;27:264270.

23 Flurkey K, Currer JM, Harrison DE: Mouse models in aging research; in Fox JG, Barthold SW, Davisson MT, Newcomer CE, Quimby FW, Smith AL (eds): The Mouse in Biomedical Research. Burlington, American College of Laboratory Animal Medicine Series, 2007, pp 637-672.

24 Neuschl C, Hantschel C, Wagener A, Schmitt AO, Illig T, Brockmann GA: A unique genetic defect on chromosome 3 is responsible for juvenile obesity in the Berlin Fat Mouse. Int J Obes 2010; 34:1706-1714.

25 Meyer CW, Wagener A, Rink N, Hantschel C, Heldmaier G, Klingenspor M, Brockmann GA High energy digestion efficiency and altered lipid metabolism contribute to obesity in BFMI mice. Obesity 2009;17:1988-1993.

26 Clee SM, Attie AD: The genetic landscape of type 2 diabetes in mice. Endocr Rev 2007;28:48-83.

-27 Mekada K, Abe K, Murakami A, Nakamura S, Nakata H, Moriwaki K, Obata Y, Yoshiki A: Genetic differences among C57BL/6 substrains. Exp Anim 2009;58:141-149.

-28 Taicher GZ, Tinsley FC, Reiderman A, Heiman ML: Quantitative magnetic resonance (QMR) method for bone and whole-body-composition analysis. Anal Bioanal Chem 2003;377:990-1002.

29 Tinsley FC, Taicher GZ, Heiman ML: Evaluation of a quantitative magnetic resonance method for mouse whole body composition analysis. Obesity 2004;12:150-160.
30 Teupser D, Tan M, Persky AD, Breslow JL: Atherosclerosis quantitative trait loci are sex- and lineage-dependent in an intercross of C57BL/6 and FVB/N low-density lipoprotein receptor-/- mice. Proc Natl Acad Sci U S A 2006;103:123-128.

31 Buchmann J, Meyer C, Neschen S, Augustin R, Schmolz K, Kluge R, Al-Hasani H, Jurgens H, Eulenberg K, Wehr R, Dohrmann C, Joost HG, Schurmann A: Ablation of the cholesterol transporter adenosine triphosphate-binding cassette transporter G1 reduces adipose cell size and protects against diet-induced obesity. Endocrinology 2007;148:1561-1573.

32 Wallace TM, Levy JC, Matthews DR: Use and abuse of HOMA modeling. Diabetes Care 2004;27: 1487-1495.

33 Lee S, Muniyappa R, Yan X, Chen H, Yue LQ, Hong EG, Kim JK, Quon MJ: Comparison between surrogate indexes of insulin sensitivity and resistance and hyperinsulinemic euglycemic clamp estimates in mice. Am J Physiol Endocrinol Metab 2008;294:E261-E270.

34 R Development Core Team: R: A Language and Environment for Statistical Computing. R Foundation for Statistical Computing, Vienna, Austria, 2011, ISBN 3-900051-07-0. www.R-project.org.

35 Elrick H, Stimmler L, Hlad CJ Jr, Arai Y: Plasma insulin response to oral and intravenous glucose administration. J Clin Endocrinol Metab 1964;24: 1076-1082.

36 Drucker DJ, Nauck MA: The incretin system: glucagon-like peptide-1 receptor agonists and dipeptidyl peptidase- 4 inhibitors in type 2 diabetes. Lancet 2006;368:1696-1705.
37 Kónya A, Wright KC, Gounis M, Kandarpa K: Animal models for artherosclerosis, restenosis, and endovascular aneurysm repair; in Conn PM (ed) Sourcebook of Models for Biomedical Research. Totowa, Humana Press, 2008, pp 369-384.

38 Benoit SC, Clegg DJ, Seeley RJ, Woods SC: Insulin and leptin as adiposity signals. Recent Prog Horm Res 2004;59:267-285.

39 Whitehead JP, Richards AA, Hickman IJ, Macdonald GA, Prins JB: Adiponectin - a key adipokine in the metabolic syndrome. Diabetes Obes Metab 2006;8:264-280.

40 Goldfine AB, Kahn CR: Adiponectin: Linking the fat cell to insulin sensitivity. Lancet 2003;362:14311432.

41 Saad MF, Knowler WC, Pettitt DJ, Nelson RG, Charles MA, Bennett PH: A two-step model for development of non-insulin-dependent diabetes. Am J Med 1991;90:229-235.

42 Karelis AD: Metabolically healthy but obese individuals. Lancet 2008;372:1281-1283.

43 Bielschowsky M, Bielschowsky F: A new strain of mice with hereditary obesity. Proc Univ Otago Med School 1953;31:29-31.

44 Nakamura M, Yamada K: Studies on a diabetic (KK) strain of the mouse. Diabetologia 1967;3:212221

45 Allan MF, Eisen EJ, Pomp D: The M16 mouse: an outbred animal model of early onset polygenic obesity and diabesity. Obes Res 2004;12:1397-1407. 